\title{
Plantas de la flora yucatanense que provocan alguna toxicidad en el humano.
}

\section{Artículo Original}

José S. Flores ${ }^{1}$, Gladiz C. O. Canto-Aviles ${ }^{2}$, Ana G. Flores-Serrano ${ }^{3}$.

${ }^{1}$ Departamento de Botánica, Lic. en Biología, Facultad de Medicina Veterinaria y Zootecnia, Universidad Autónoma de Yucatán, ${ }^{2}$ Centro Médico de las Américas (CMA), ${ }^{3}$ Departamento de Inmunología, Centro de Investigaciones Regionales "Dr. Hideyo Noguchi", Universidad Autónoma de Yucatán, Mérida, Yucatán, México.

\section{RESUMEN.}

Objetivo. El presente trabajo contiene información de plantas de la flora yucatanense que ocasionan alguna toxicidad en el humano, en él se mencionan la especie, la familia, el nombre común, la parte de la planta que produce la toxicidad, los efectos de su intoxicación, la distribución de ésta en la Península y el tipo de vegetación en que se localiza.

Material y métodos. Para obtener la información se revisaron las bases de datos del Programa Etnoflora Yucatanense que se desarrolla en la Facultad de Medicina Veterinaria y Zootecnia; se realizaron entrevistas en hospitales, clínicas y en la Cruz Roja, especialmente en la ciudad de Mérida, esto con el objeto de detectar los casos de pacientes tratados por intoxicación con plantas. Adicionalmente se realizaron entrevistas al respecto en 25 comunidades mayas, especialmente se entrevistó a los "H'menes" y a 25 personas adultas, haciendo un total de 300 encuestas. Las plantas tóxicas colectadas se herborizaron en el herbario de la Universidad Autónoma de Yucatán. Resultados. En total se obtuvo información de 50 especies correspondientes a 17 familias, y se encontró que 23 de ellas (46\%) además son plantas ornamentales.

Conclusiones. Las plantas tóxicas de la Península de Yucatán representan el 2.27\% del total de especies. La importancia de su identificación y reconocimiento de su toxicidad en las personas.

(Rev Biomed 2001; 12:86-96)

Palabras clave: plantas tóxicas para humanos, flora yucatanense.

\section{SUMMARY.}

Yucatanensis flora which causes some toxicity in humans.

Objective. This paper contains information on plants of the yucatanensis flora which cause some

Solicitud de sobretiros: Dr. José S. Flores-Guido, Depto. de Botánica, Fac. de Medicina Veterinaria y Zootecnia, Universidad Autónoma de Yucatán, Carr. Mérida-X'matkuil Km. 15.5, Mérida, Yucatán, México. $\quad$ Tel. (9) 942-32-16 Ext. 26 Recibido el 14/Abril/2000. Aceptado para publicación el 28/Septiembre/2000. 
JS Flores, GCO Canto-Aviles, AG Flores-Serrano.

toxicity in the human being. It mentions their species, their family, their common name, the part of the plant that causes toxicity, their distribution in the Peninsula, their intoxication effects and the type of vegetation where they are located.

Material and methods. To obtain the information, the Etnoflora Yucatanensis Programa from the Faculty of Veterinary Medicine and Husbandry data bases were revised; interviews in hospitals, clinics and the Red Cross hospital were carried out, especially in Merida city, with the objective of detecting applied the cases of patients treated for plant intoxication. Interviews were also to "H'menes" and 25 adults in 25 mayan communities, a total of 300 interviews were made. Results. The toxic plants were collected and herborized at the herbarium of the Autonomous University of Yucatan. In total, information from 50 species corresponding to 17 families was obtained; it was found that 23 (46\%) were also ornamental plants.

Conclusions. The main reason to know these plants in order to avoid them, since some of them can even cause death.

(Rev Biomed 2001; 12:86-96)

Key words: Toxic plants for humans, yucatanensis flora.

\section{INTRODUCCIÓN.}

El conocimiento del recurso vegetal ha sido una meta del hombre desde que éste aparece en la escala zoológica; así la relación planta-hombre es tan antigua como este mismo. Dicha relación es notable por la gran diversidad de usos que han sido revelados a través de los estudios etnobotánicos, como por ejemplo: alimento, medicina, defensa, construcción, vestido, colorante y forrajes. Sin embargo las plantas también pueden contener sustancias nocivas que pueden ocasionar trastornos al ser humano, los cuales van desde irritaciones, comezón y quemaduras en la piel, hasta vómitos, diarreas, e incluso la muerte. Se les llama plantas tóxicas a aquellas que contienen alguna sustancia química capaz de producir algún tipo de trastorno a la salud del ser humano.

Debido a que se ha observado que algunas de las plantas de uso común en la población son plantas tóxicas, consideramos que es de suma importancia el tener un conocimiento detallado de cuáles son estas plantas y su distribución en la Península de Yucatán. Es por esta razón que se decidió realizar el presente trabajo, el cual se inició en 1989 y se terminó en 1997 dentro del Programa Etnoflora Yucatanense que se llevó a cabo en el Departamento de Botánica de la Lic. en Biología de la Facultad de Medicina Veterinaria y Zootecnia y en la Facultad de Química y con el apoyo del Departamento de Investigaciones Regionales "Dr. Hideyo Noguchi" de la Universidad Autónoma de Yucatán (UADY).

\section{MATERIAL Y MÉTODOS.}

Se hizo una recopilación bibliográfica referente a plantas tóxicas de México para verificar su existencia en la Península de Yucatán. Por otra parte, se buscó información de reportes clínicos de personas intoxicadas por alguna planta. Para ello se realizaron entrevistas en clínicas, hospitales y Cruz Roja del estado de Yucatán. Asimismo, se entrevistaron a los curanderos de 25 comunidades mayas dentro de la Península de Yucatán, así como a los H'menes (sacerdote de la cultura maya diestro en el arte de la curación) y a 10 personas adultas en cada poblado, realizándose un total de 275 entrevistas. En las entrevistas se usó la ficha que se ha diseñado para ingresar información al Banco de Datos Etnobotánicos de la Península de Yucatán (BADEPY), el cual forma parte del Programa de Etnoflora Yucatanense de la UADY. Finalmente se hicieron colectas de las plantas reportadas como tóxicas en la bibliografía y en las entrevistas realizadas, las cuales se depositaron en el herbario de la misma casa de estudios.

\section{Revista Biomédica}


Flora yucatanense tóxica.

\section{RESULTADOS.}

De la revisión bibliográfica y de las entrevistas se obtuvo una lista de 50 plantas tóxicas distribuidas dentro de la Península de Yucatán (cuadro 1). Es importante resaltar que 47 de las 50 plantas reportadas son introducidas. En la figura 1 se muestra la distribución geográfica de las 25 comunidades mayas consideradas para las entrevistas. En la figura 2 se muestran 5 de las plantas tóxicas ornamentales encontradas en la Península de Yucatán.

Cuadro 1

Lista de especies tóxicas en la Península de Yucatán. (Parte 1)

\begin{tabular}{|c|c|c|c|c|}
\hline $\begin{array}{l}\text { Nombre científico } \\
\text { y nombre común }\end{array}$ & Familia & Parte tóxica & Distribución & Efectos \\
\hline $\begin{array}{l}\text { Anacardium occidentale L.* } \\
\text { "Marañón" }\end{array}$ & Anacardiaceae & $\begin{array}{l}\text { Tallo, hojas, } \\
\text { fruto y semillas }\end{array}$ & $\begin{array}{l}\text { Huertos } \\
\text { familiares }\end{array}$ & $\begin{array}{l}\text { Quemaduras en la } \\
\text { piel y mucosas }\end{array}$ \\
\hline $\begin{array}{l}\text { Mangifera indica L. * } \\
\text { "Mango" }\end{array}$ & Anacardiaceae & $\begin{array}{l}\text { Látex de hojas } \\
\text { y frutos }\end{array}$ & $\begin{array}{l}\text { Huertos } \\
\text { familiares }\end{array}$ & $\begin{array}{l}\text { El látex produce quemaduras en } \\
\text { la piel y mucosas. El fruto verde } \\
\text { puede producir diarrea. }\end{array}$ \\
\hline $\begin{array}{l}\text { Metopium brownei } \\
\text { (Jacq.) Urban. } \\
\text { "Che che'en" }\end{array}$ & Anacardiaceae & $\begin{array}{l}\text { El látex del } \\
\text { tallo y hojas }\end{array}$ & $\begin{array}{l}\text { Matorrales de } \\
\text { duna y en selvas } \\
\text { medianas y bajas }\end{array}$ & $\begin{array}{l}\text { Las hojas producen sustancias } \\
\text { volátiles que producen quemaduras } \\
\text { en todo el cuerpo. }\end{array}$ \\
\hline $\begin{array}{l}\text { Rhus radicans L. } \\
\text { "Sak cheche'en" }\end{array}$ & Anacardiaceae & Hojas y tallo & Selvas medianas & $\begin{array}{l}\text { Produce graves quemaduras. } \\
\text { Puede producirles } \\
\text { inflamación de cara y manos. }\end{array}$ \\
\hline $\begin{array}{l}\text { Nerium oleander L. * } \\
\text { "Adelfa, Narciso" }\end{array}$ & Apocynaceae & Toda la planta & $\begin{array}{l}\text { Jardines y } \\
\text { parques }\end{array}$ & $\begin{array}{l}\text { Su ingestión afecta a los nervios } \\
\text { faciales, produce náuseas, vómitos, } \\
\text { cólicos, diarrea, somnolencia, } \\
\text { convulsiones, e incluso } \\
\text { estado de coma y la muerte. }\end{array}$ \\
\hline $\begin{array}{l}\text { Rauvolfia tetraphylla L. } \\
\text { "Kabal muk" }\end{array}$ & Apocynaceae & $\begin{array}{l}\text { Hojas, corteza } \\
\text { y frutos }\end{array}$ & $\begin{array}{l}\text { Vegetación } \\
\text { secundaria } \\
\text { derivada de } \\
\text { selvas bajas } \\
\text { caducifolias y } \\
\text { medianas }\end{array}$ & $\begin{array}{l}\text { Diarrea, náuseas, vómitos, } \\
\text { disminución de la presión } \\
\text { arterial, depresión, } \\
\text { desvanecimiento, } \\
\text { convulsiones y la muerte. }\end{array}$ \\
\hline $\begin{array}{l}\text { Thevetia ahouai (L.) } \\
\text { A. DC. } \\
\text { "Akit, huevos de perro" }\end{array}$ & Apocynaceae & $\begin{array}{l}\text { Frutos y } \\
\text { semillas }\end{array}$ & $\begin{array}{l}\text { Ornamental y en } \\
\text { selvas medianas } \\
\text { de la Península }\end{array}$ & $\begin{array}{l}\text { Trastornos del sistema nervioso } \\
\text { central y del corazón; y puede } \\
\text { provocar la muerte. }\end{array}$ \\
\hline $\begin{array}{l}\text { Anthurium aemulum } \\
\text { Schott. } \\
\text { "Xnej oochil, xoochil" }\end{array}$ & Araceae & Hojas y tallo & $\begin{array}{l}\text { Ornamental y } \\
\text { en selvas }\end{array}$ & $\begin{array}{l}\text { La sabia produce comezón } \\
\text { en la boca y mucosas, así } \\
\text { como inflamación, pudiendo } \\
\text { provocar asfixia. }\end{array}$ \\
\hline
\end{tabular}

* Plantas introducidas a la Península de Yucatán. 
JS Flores, GCO Canto-Aviles, AG Flores-Serrano.

Cuadro 1

Lista de especies tóxicas en la Península de Yucatán. (Parte 2)

\begin{tabular}{|c|c|c|c|c|}
\hline $\begin{array}{l}\text { Nombre científico } \\
\text { y nombre común }\end{array}$ & Familia & Parte tóxica & Distribución & Efectos \\
\hline $\begin{array}{l}\text { Anthurium crassinervium } \\
\text { (Jacq.) Schott. * } \\
\text { "Kiilbal chaak" }\end{array}$ & Araceae & Hojas y tallo & Ornamental & $\begin{array}{l}\text { La sabia produce comezón } \\
\text { en la boca y mucosas, así } \\
\text { como inflamación, pudiendo } \\
\text { provocar asfixia. }\end{array}$ \\
\hline $\begin{array}{l}\text { Anthurium } \\
\text { schlechtendalii Kunth. } \\
\text { "Batun, kiilbal chaak" }\end{array}$ & Araceae & Hojas y tallo & Ornamental & $\begin{array}{l}\text { La sabia produce comezón } \\
\text { en la boca y mucosas, así } \\
\text { como inflamación, pudiendo } \\
\text { provocar asfixia. }\end{array}$ \\
\hline $\begin{array}{l}\text { Anthurium tetragonum } \\
\text { var. yucatanense Engl. } \\
\text { "Kiilbal chaak" }\end{array}$ & Araceae & $\begin{array}{l}\text { Hojas, tallo } \\
\text { y frutos }\end{array}$ & $\begin{array}{l}\text { Ornamental y } \\
\text { en selvas }\end{array}$ & $\begin{array}{l}\text { La sabia produce comezón } \\
\text { en la boca y mucosas, así } \\
\text { como inflamación, pudiendo } \\
\text { provocar asfixia. }\end{array}$ \\
\hline $\begin{array}{l}\text { Caladium bicolor Ventl.* } \\
\text { "Corazón de María" }\end{array}$ & Araceae & Hojas, tallo & $\begin{array}{l}\text { Ornamental } \\
\text { y frutos }\end{array}$ & $\begin{array}{l}\text { La sabia produce comezón } \\
\text { en la boca y mucosas, así } \\
\text { como inflamación, pudiendo } \\
\text { provocar asfixia. }\end{array}$ \\
\hline $\begin{array}{l}\text { Diffenbachia seguine } \\
\text { (L.) Schotf.* } \\
\text { "Hoja de la suerte, } \\
\text { Costarica" }\end{array}$ & Araceae & Hojas y tallo & Ornamental & $\begin{array}{l}\text { La sabia produce comezón } \\
\text { en la boca y mucosas, así } \\
\text { como inflamación, pudiendo } \\
\text { provocar asfixia. }\end{array}$ \\
\hline $\begin{array}{l}\text { Monstera deliciosa } \\
\text { Liebm. } \\
\text { "Hojas de la suerte" }\end{array}$ & Araceae & $\begin{array}{l}\text { Hojas, tallo } \\
\text { y frutos }\end{array}$ & $\begin{array}{l}\text { Ornamental y } \\
\text { en selvas } \\
\text { (lianas) }\end{array}$ & $\begin{array}{l}\text { La sabia produce comezón } \\
\text { en la boca y mucosas, así } \\
\text { como inflamación, pudiendo } \\
\text { provocar asfixia. }\end{array}$ \\
\hline $\begin{array}{l}\text { Syngonium podophyllum } \\
\text { Schott } \\
\text { "Xoochil" }\end{array}$ & Araceae & Hojas y tallo & $\begin{array}{l}\text { Ornamental y } \\
\text { en selvas } \\
\text { (lianas) }\end{array}$ & $\begin{array}{l}\text { La sabia produce comezón } \\
\text { en la boca y mucosas, así } \\
\text { como inflamación, pudiendo } \\
\text { provocar asfixia. }\end{array}$ \\
\hline $\begin{array}{l}\text { Xanthosoma yucatanense } \\
\text { Engler } \\
\text { "Kukut makal" }\end{array}$ & Araceae & Hojas y tallo & $\begin{array}{l}\text { Ornamental y } \\
\text { en selvas }\end{array}$ & $\begin{array}{l}\text { Su contacto causa } \\
\text { comezón y provoca } \\
\text { ronchas. }\end{array}$ \\
\hline $\begin{array}{l}\text { Asclepias curassavica L. } \\
\text { "Anal, anal k'aak"" }\end{array}$ & Asclepiadaceae & Hojas y frutos & $\begin{array}{l}\text { Vegetación } \\
\text { secundaria } \\
\text { derivada de } \\
\text { selvas, en lu- } \\
\text { gares húmedos } \\
\text { y sombríos. }\end{array}$ & $\begin{array}{l}\text { Si se mastica produce } \\
\text { diarrea e incordinación, } \\
\text { parálisis muscular, } \\
\text { dificultad respiratoria, } \\
\text { disturbios cardiacos y } \\
\text { puede provoca la muerte. }\end{array}$ \\
\hline
\end{tabular}

* Plantas introducidas a la Península de Yucatán.

\section{Revista Biomédica}


Flora yucatanense tóxica.

Cuadro 1

Lista de especies tóxicas en la Península de Yucatán. (Parte 3)

\begin{tabular}{|c|c|c|c|c|}
\hline Nombre científico & Familia & Parte tóxica & Distribución & Efectos \\
\hline $\begin{array}{l}\text { Calotropis gigantea L. } \\
\text { "Huevo de toro" }\end{array}$ & Asclepiadaceae & $\begin{array}{l}\text { Hojas, tallo } \\
\text { y frutos }\end{array}$ & $\begin{array}{l}\text { Vegetación de } \\
\text { dunas y matorral } \\
\text { de duna }\end{array}$ & $\begin{array}{l}\text { El látex irrita y produce } \\
\text { quemaduras en la piel } \\
\text { y mucosas. }\end{array}$ \\
\hline $\begin{array}{l}\text { Cordia dentata Poir.* } \\
\text { "Triguilote" }\end{array}$ & Boraginaceae & Frutos & $\begin{array}{l}\text { Cultivado en } \\
\text { huertos } \\
\text { familiares. }\end{array}$ & $\begin{array}{l}\text { Si se ingiere puede } \\
\text { provocar diarrea }\end{array}$ \\
\hline $\begin{array}{l}\text { Bromelia karatas L. } \\
\text { "Chak ch'am" }\end{array}$ & Bromeliaceae & Frutos & $\begin{array}{l}\text { Estrato herbáceo } \\
\text { de selvas, en } \\
\text { huertos } \\
\text { familiares y en } \\
\text { cercas vivas. }\end{array}$ & $\begin{array}{l}\text { Si se ingiere el fruto } \\
\text { produce escozor e } \\
\text { inflamación en los labios. }\end{array}$ \\
\hline $\begin{array}{l}\text { Bromelia pinguin L. } \\
\text { "Ts'albay" }\end{array}$ & Bromeliaceae & Frutos & $\begin{array}{l}\text { Estrato bajo de } \\
\text { selvas bajas y en } \\
\text { cercas vivas. }\end{array}$ & $\begin{array}{l}\text { Si se ingiere produce } \\
\text { comezón en la boca } \\
\text { e inflama los labios. }\end{array}$ \\
\hline $\begin{array}{l}\text { Commelina elegans } \\
\text { H.B. \& K. } \\
\text { "Kabal siit, kaba siit, } \\
\text { ya'ax puk'im" }\end{array}$ & Commelinaceae & Toda la planta & $\begin{array}{l}\text { Vegetación } \\
\text { secundaria } \\
\text { derivada de } \\
\text { selvas y en } \\
\text { jardines. }\end{array}$ & $\begin{array}{l}\text { La sabia produce comezón } \\
\text { en la boca y mucosas, así } \\
\text { como inflamación, pudiendo } \\
\text { provocar asfixia. }\end{array}$ \\
\hline $\begin{array}{l}\text { Rhoeo discolor (L'Her.) } \\
\text { Hance ex Walp. } \\
\text { "Chaktsan, maguey rojo" }\end{array}$ & Commelinaceae & Hojas & $\begin{array}{l}\text { Vegetación } \\
\text { herbácea de } \\
\text { selvas y en } \\
\text { jardines. }\end{array}$ & $\begin{array}{l}\text { La sabia produce serias } \\
\text { quemaduras en la piel. }\end{array}$ \\
\hline $\begin{array}{l}\text { Dioscorea alata L. } \\
\text { "Ak' makal" }\end{array}$ & Dioscoreaceae & $\begin{array}{l}\text { Tubérculo } \\
\text { (raíz) }\end{array}$ & $\begin{array}{l}\text { Cultivado en } \\
\text { milpas y huertos } \\
\text { familiares. }\end{array}$ & $\begin{array}{l}\text { Ingerida puede } \\
\text { producir aborto. }\end{array}$ \\
\hline $\begin{array}{l}\text { Dioscorea floribunda } \\
\text { Mart. \& Gal. } \\
\text { "Makal k'uuch" }\end{array}$ & Dioscoreaceae & $\begin{array}{l}\text { Tubérculo } \\
\text { (raíz) }\end{array}$ & $\begin{array}{l}\text { Vegetación } \\
\text { secundaria } \\
\text { derivada de } \\
\text { selvas. }\end{array}$ & $\begin{array}{l}\text { Ingerida puede } \\
\text { producir aborto. }\end{array}$ \\
\hline $\begin{array}{l}\text { Adelia barbinervis } \\
\text { Schlecht. \& Cham. } \\
\text { "Puuts' mukuy" }\end{array}$ & Euphorbiaceae & Hojas y tallo & $\begin{array}{l}\text { Vegetación } \\
\text { secundaria } \\
\text { derivada de } \\
\text { selvas. }\end{array}$ & $\begin{array}{l}\text { Su contacto causa } \\
\text { comezón y provoca } \\
\text { ronchas. }\end{array}$ \\
\hline $\begin{array}{l}\text { Cnidoscolus aconitifolius } \\
\text { (Mill.) I.M. Johnston. } \\
\text { "Chaay" }\end{array}$ & Euphorbiaceae I & Hojas y tallo & $\begin{array}{l}\text { Vegetación } \\
\text { secundaria } \\
\text { derivada de } \\
\text { selvas bajas. }\end{array}$ & $\begin{array}{l}\text { Produce inflamación al } \\
\text { contacto causa comezón } \\
\text { y provoca ronchas. }\end{array}$ \\
\hline
\end{tabular}

* Plantas introducidas a la Península de Yucatán.

Vol. 12/No. 2/Abril-Junio, 2001 
JS Flores, GCO Canto-Aviles, AG Flores-Serrano.

Cuadro 1

Lista de especies tóxicas en la Península de Yucatán. (Parte 4)

\begin{tabular}{|c|c|c|c|c|}
\hline $\begin{array}{l}\text { Nombre científico } \\
\text { y nombre común }\end{array}$ & Familia & Parte tóxica & Distribución & Efectos \\
\hline $\begin{array}{l}\text { Cnidoscolus chayamansa } \\
\text { McVaugh. } \\
\text { "Chaay" }\end{array}$ & Euphorbiaceae & Hojas y tallo & $\begin{array}{l}\text { Cultivado en } \\
\text { huertos. }\end{array}$ & $\begin{array}{l}\text { Su contacto causa } \\
\text { comezón y provoca } \\
\text { ronchas. }\end{array}$ \\
\hline $\begin{array}{l}\text { Cnidoscus souzae } \\
\text { McVaugh. } \\
\text { "Ch'iinchay" }\end{array}$ & Euphorbiaceae & Hojas y tallo & $\begin{array}{l}\text { Vegetación } \\
\text { secundaria }\end{array}$ & $\begin{array}{l}\text { Su contacto causa } \\
\text { comezón y provoca } \\
\text { ronchas. }\end{array}$ \\
\hline $\begin{array}{l}\text { Croton humilis L. } \\
\text { "Ik ja'aban" }\end{array}$ & Euphorbiaceae & Hojas y flores & $\begin{array}{l}\text { Vegetación } \\
\text { secundaria } \\
\text { derivada de } \\
\text { selvas bajas. }\end{array}$ & $\begin{array}{l}\text { El rocío retenido en sus } \\
\text { flores y frutos, puede } \\
\text { producir quemaduras en la } \\
\text { cornea, que si son graves } \\
\text { resultan en ceguera. }\end{array}$ \\
\hline $\begin{array}{l}\text { Dalechampia } \\
\text { scandens L. } \\
\text { "Mo'ol koj, xmo'ol koj" }\end{array}$ & Euphorbiaceae & Hojas y tallo & $\begin{array}{l}\text { Vegetación se- } \\
\text { cundaria deri- } \\
\text { vada de selva } \\
\text { baja caducifolia }\end{array}$ & $\begin{array}{l}\text { Sus pelos urticantes } \\
\text { pueden causar ardor, dolor, } \\
\text { excoriación e hinchazón en } \\
\text { las partes del cuerpo. }\end{array}$ \\
\hline $\begin{array}{l}\text { Euphorbia lactea Haw.* } \\
\text { "Lechosa africana" } \\
\text { Cultivada }\end{array}$ & Euphorbiaceae & Tallo & $\begin{array}{l}\text { Ornamental y } \\
\text { en cercas vivas. }\end{array}$ & $\begin{array}{l}\text { El látex es necrosante y } \\
\text { puede causar graves } \\
\text { quemaduras en la piel. }\end{array}$ \\
\hline $\begin{array}{l}\text { Euphorbia tirucalli L.* } \\
\text { "Esqueleto" }\end{array}$ & Euphorbiaceae & Tallo & $\begin{array}{l}\text { Ornamental en } \\
\text { jardines y cer- } \\
\text { cas vivas. }\end{array}$ & $\begin{array}{l}\text { El látex es necrosante y } \\
\text { puede causar graves } \\
\text { quemaduras a la piel. }\end{array}$ \\
\hline $\begin{array}{l}\text { Hura polyandra } \\
\text { Baillon.* } \\
\text { "Haba, soliman che"" }\end{array}$ & Euphorbiaceae & $\begin{array}{l}\text { Hojas, tallo, } \\
\text { frutos y } \\
\text { semillas }\end{array}$ & $\begin{array}{l}\text { Selvas y } \\
\text { ornamentado } \\
\text { en parques }\end{array}$ & $\begin{array}{l}\text { El látex puede causar graves } \\
\text { quemaduras. El fruto y semillas, } \\
\text { aún sin ser consumidos, pueden } \\
\text { causar náuseas y vómitos, fuerte } \\
\text { irritación gastrointestinal, } \\
\text { inflamación de mucosas y en } \\
\text { ocasiones la muerte. }\end{array}$ \\
\hline $\begin{array}{l}\text { Jatropha curcas L.* } \\
\text { "Sikilte', piñonsillo" }\end{array}$ & Euphorbiacaea & Semillas & $\begin{array}{l}\text { Cercas vivas } \\
\text { y ornamentado } \\
\text { en parques. }\end{array}$ & $\begin{array}{l}\text { Al ser consumidas en } \\
\text { abundancia puede provocar } \\
\text { diarreas, espasmos musculares y } \\
\text { dilatación de pupilas. }\end{array}$ \\
\hline $\begin{array}{l}\text { Jatropha multifida L.* } \\
\text { "Palmeado" }\end{array}$ & Euphorbiaceae & $\begin{array}{l}\text { Látex y } \\
\text { semillas. }\end{array}$ & $\begin{array}{l}\text { Ornamentado } \\
\text { en jardines. }\end{array}$ & $\begin{array}{l}\text { El látex puede causar escozor. } \\
\text { Las semillas causan vómitos y } \\
\text { diarrea al ser consumidas. }\end{array}$ \\
\hline $\begin{array}{l}\text { Pedilanthus itzaeus } \\
\text { Millsp. } \\
\text { "Ya'ax jalal che"" }\end{array}$ & Euphorbiaceae & $\begin{array}{l}\text { Hojas, tallo } \\
\text { y látex. }\end{array}$ & $\begin{array}{l}\text { Ornamental y } \\
\text { en vegetación } \\
\text { secundaria. }\end{array}$ & $\begin{array}{l}\text { Si se consumen pueden } \\
\text { causar cólicos intensos, } \\
\text { diarrea y vómitos. }\end{array}$ \\
\hline
\end{tabular}

* Plantas introducidas a la Península de Yucatán. 
Flora yucatanense tóxica.

\section{Cuadro 1}

Lista de especies tóxicas en la Península de Yucatán. (Parte 5)

\begin{tabular}{|c|c|c|c|c|}
\hline $\begin{array}{l}\text { Nombre científico } \\
\text { y nombre común }\end{array}$ & Familia & Parte tóxica & Distribución & Efectos \\
\hline $\begin{array}{l}\text { Ricinus communis L.* } \\
\text { "K'o'och" }\end{array}$ & Euphorbiaceae & Semillas & $\begin{array}{l}\text { Ornamental- } \\
\text { escapada. }\end{array}$ & $\begin{array}{l}\text { Ardor en la boca, garganta, sed, } \\
\text { náuseas, vómitos, diarrea violenta, } \\
\text { sudoración, dolor abdominal, visión } \\
\text { escasa, daños al hígado y riñón, } \\
\text { somnolencia, espasmos tetánicos, } \\
\text { convulsión y muerte. }\end{array}$ \\
\hline $\begin{array}{l}\text { Sebastiana adenophora } \\
\text { Pax \& Hoffm. } \\
\text { "K'aan chunuup" }\end{array}$ & Euphorbiaceae & Hojas y tallo & $\begin{array}{l}\text { Vegetación } \\
\text { secundaria } \\
\text { derivada de } \\
\text { selvas bajas. }\end{array}$ & $\begin{array}{l}\text { El látex es irritante a las personas } \\
\text { alérgicas puede causarles } \\
\text { inflamación. }\end{array}$ \\
\hline $\begin{array}{l}\text { Tragia yucatanensis } \\
\text { Millsp. } \\
\text { "P'oop'ox" }\end{array}$ & Euphorbiaceae & Hojas y tallo & $\begin{array}{l}\text { Vegetación } \\
\text { secundaria } \\
\text { derivada de } \\
\text { selvas. }\end{array}$ & $\begin{array}{l}\text { Posee pelos que pueden } \\
\text { causar irritaciones } \\
\text { dolorosas en la piel. }\end{array}$ \\
\hline $\begin{array}{l}\text { Erythrina standleyana } \\
\text { Krukoff } \\
\text { "Chak ch'oobenche'" }\end{array}$ & Leguminosae & $\begin{array}{l}\text { Hojas, frutos } \\
\text { y semillas. }\end{array}$ & $\begin{array}{l}\text { Vegetación de } \\
\text { matorral de } \\
\text { duna y } \\
\text { ornamental. }\end{array}$ & $\begin{array}{l}\text { Al ser consumidas las hojas y } \\
\text { flores provocan somnolencia. Las } \\
\text { semillas producen graves trastornos } \\
\text { estomacales acompañados } \\
\text { de vómitos. }\end{array}$ \\
\hline $\begin{array}{l}\text { Gronovia scandens L. } \\
\text { "Beel muuch, laal, laal } \\
\text { muk, laal muuch" }\end{array}$ & Loasaceae & Hojas y tallo & $\begin{array}{l}\text { Vegetación } \\
\text { secundaria } \\
\text { derivada de } \\
\text { selvas bajas } \\
\text { y medianas }\end{array}$ & $\begin{array}{l}\text { Contiene pelos que al } \\
\text { contacto con la piel dan la } \\
\text { sensación de quemaduras, } \\
\text { provoca ardor y excoriaciones. }\end{array}$ \\
\hline $\begin{array}{l}\text { Thalia geniculata L.* } \\
\text { "Kento"" }\end{array}$ & Marantaceae & Tallos & Ornamental & $\begin{array}{l}\text { Al masticarlo provoca } \\
\text { inflamación de mucosas, } \\
\text { comezón, dolor y asfixia. }\end{array}$ \\
\hline $\begin{array}{l}\text { Melia azedarach L.* } \\
\text { "Paraíso" }\end{array}$ & Meliaceae & Hojas y frutos & Ornamental & $\begin{array}{l}\text { Las hojas y frutos provocan cólicos } \\
\text { violentos, diarreas con sangre, } \\
\text { convulsiones, y muerte. }\end{array}$ \\
\hline $\begin{array}{l}\text { Argemone mexicana L. } \\
\text { "Toluache" }\end{array}$ & Papaveraceae & $\begin{array}{l}\text { Raíces, hojas } \\
\text { y semillas }\end{array}$ & $\begin{array}{l}\text { Vegetación } \\
\text { secundaria } \\
\text { derivada de } \\
\text { selvas. }\end{array}$ & $\begin{array}{l}\text { Diarreas y vómitos, } \\
\text { trastornos circulatorios, } \\
\text { nerviosos y respiratorios, } \\
\text { alucinaciones y locura. }\end{array}$ \\
\hline $\begin{array}{l}\text { Datura candida } \\
\text { (Persson) Pasq.* } \\
\text { "Floripondia" }\end{array}$ & Solanaceae & Hojas y flores & Ornamental & $\begin{array}{l}\text { Las flores pueden ocasionar } \\
\text { somnolencia al ser olido por tiempo } \\
\text { prolongado. En infusión provoca } \\
\text { sequedad en la boca, pulso y } \\
\text { respiración rápida, parálisis y muerte } \\
\text { por asfixia. }\end{array}$ \\
\hline
\end{tabular}

* Plantas introducidas a la Península de Yucatán. 
JS Flores, GCO Canto-Aviles, AG Flores-Serrano.

Cuadro 1

Lista de especies tóxicas en la Península de Yucatán. (Parte 6)

\begin{tabular}{|c|c|c|c|c|}
\hline $\begin{array}{l}\text { Nombre científico } \\
\text { y nombre común }\end{array}$ & Familia & Parte tóxica & Distribución & Efectos \\
\hline $\begin{array}{l}\text { Datura inoxia Miller } \\
\text { "Chaniko'" }\end{array}$ & Solanaceae & $\begin{array}{l}\text { Hojas, flores } \\
\text { y semillas }\end{array}$ & $\begin{array}{l}\text { Vegetación } \\
\text { secundaria } \\
\text { derivada de } \\
\text { selvas y } \\
\text { ornamental en } \\
\text { jardines. }\end{array}$ & $\begin{array}{l}\text { Su consumo provoca problemas } \\
\text { en la visión, somnolencia, } \\
\text { temperatura alta, aceleración } \\
\text { alta, aceleración de las palpitaciones } \\
\text { cardiacas, trastornos mentales, } \\
\text { convulsiones y puede ocasionar la } \\
\text { muerte. }\end{array}$ \\
\hline $\begin{array}{l}\text { Solanum mammosum L.* } \\
\text { "Chichigua, chichita" }\end{array}$ & Solanaceae & $\begin{array}{l}\text { Frutos y } \\
\text { semillas }\end{array}$ & Ornamental & $\begin{array}{l}\text { Al ser consumidos produce } \\
\text { excitación y delirio, locura, } \\
\text { aceleración de latidos, } \\
\text { asfixia y muerte. }\end{array}$ \\
\hline $\begin{array}{l}\text { Urera baccifera } \\
\text { (L.) Gaudich } \\
\text { "Lal" }\end{array}$ & Urticaceae & Hojas y tallo & $\begin{array}{l}\text { Cercas vivas y } \\
\text { en selvas bajas }\end{array}$ & $\begin{array}{l}\text { Las espinas inyectan sustancias } \\
\text { que causan inflamación en las } \\
\text { partes afectadas y dolor. }\end{array}$ \\
\hline $\begin{array}{l}\text { Zamia lodigesii Miq. } \\
\text { "Chacqua" }\end{array}$ & Zamiaceae & Tubérculo & Palmita & $\begin{array}{l}\text { Trastornos digestivos, derrame intes- } \\
\text { tinal, fuertes dolores y la muerte. }\end{array}$ \\
\hline
\end{tabular}

* Plantas introducidas a la Península de Yucatán.

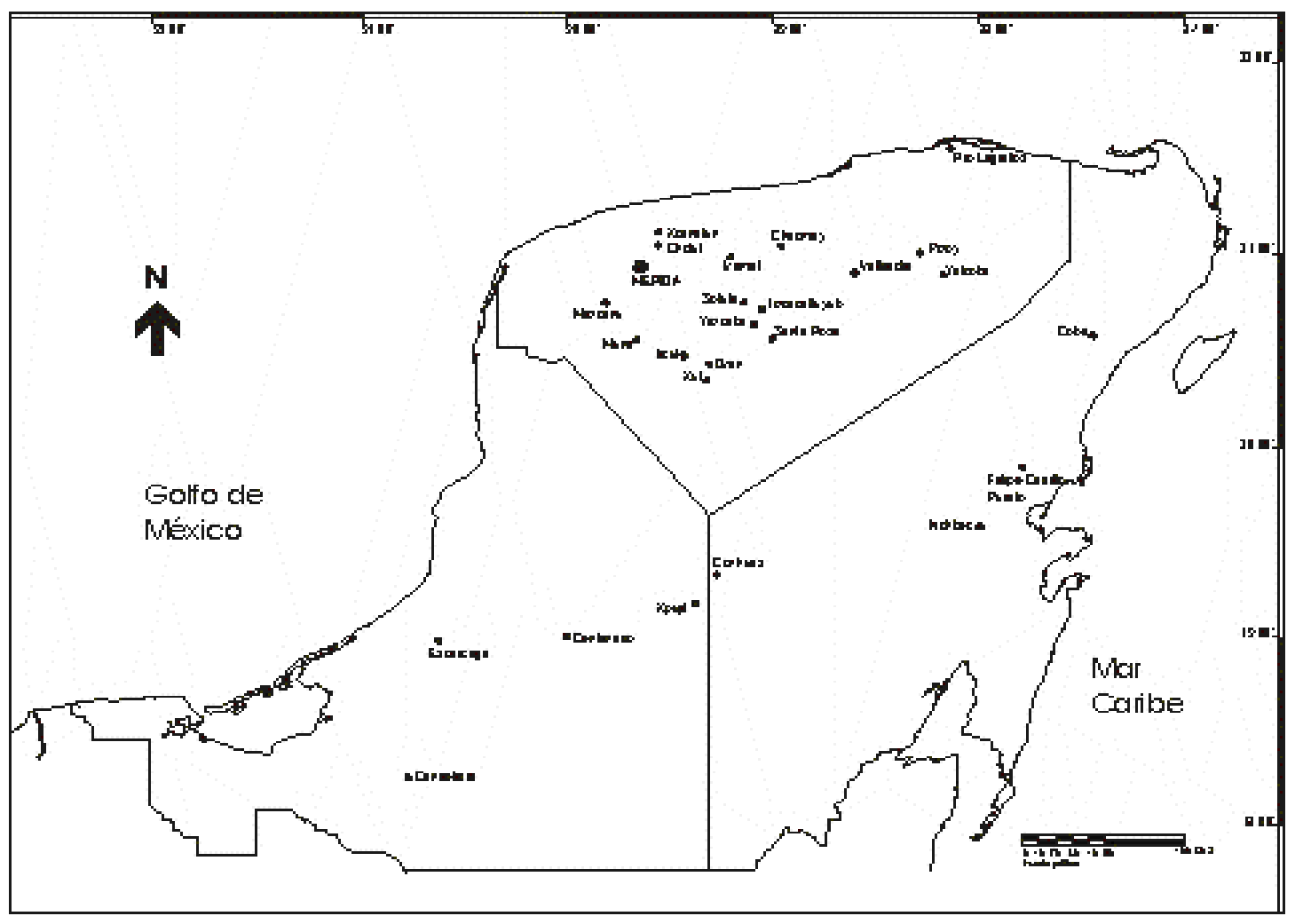

Figura 1.- Comunidades mayas en las que se estudiaron las plantas con toxicidad para el humano. 


\section{Flora yucatanense tóxica.}

\section{DISCUSIÓN.}

Se encontraron 50 plantas tóxicas distribuidas en la Península de Yucatán (5,6), que representan únicamente el $2.27 \%$ del total de especies que componen la flora peninsular.

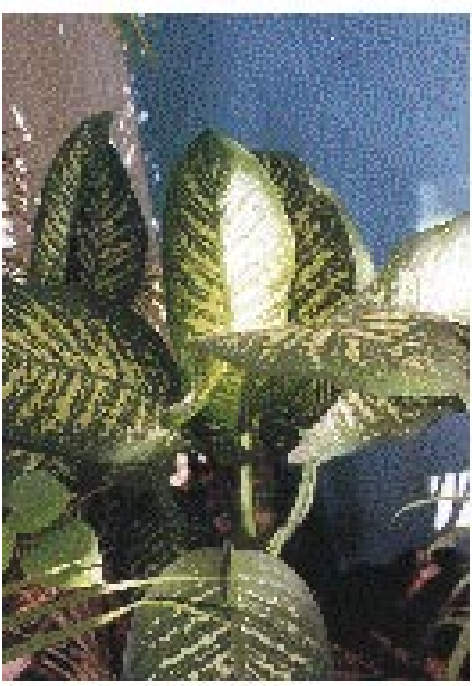

a

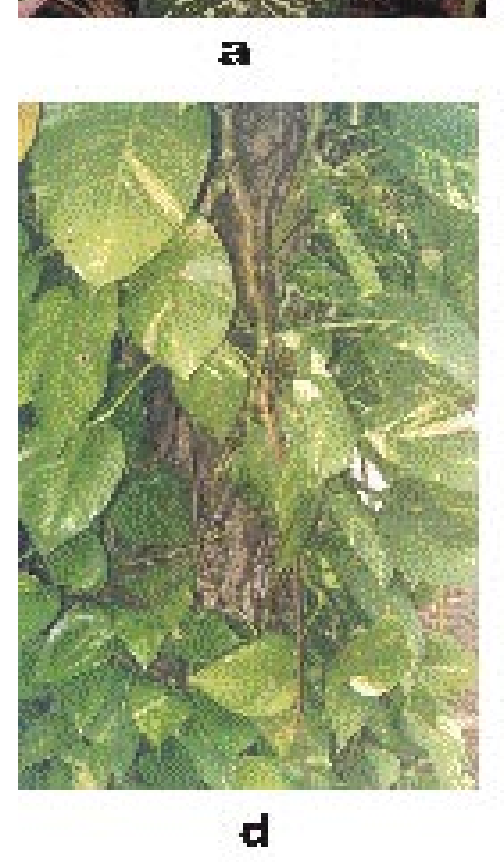

Respecto a lo reportado por Canto Avilés en 1990 (3), quien hizo un listado de planta tóxicas para humano y ganado en el estado de Yucatán, se obtuvo un incremento de dos especies. A lo largo de este estudio se observó que en realidad hay

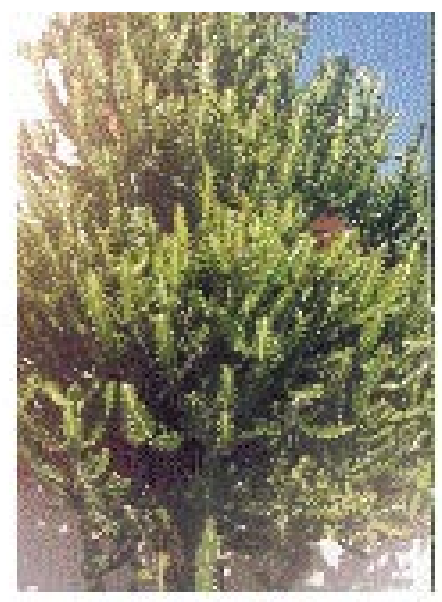

b
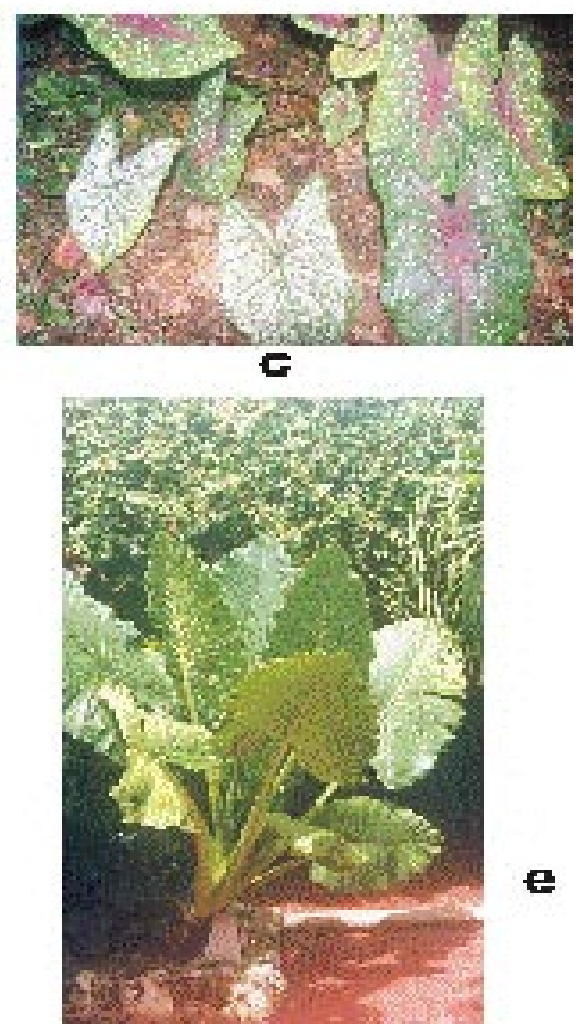

Figura 2. a- Diffenbachia seguine (L) Schoff. Nombre común: "Hojas de la suerte". b. Euphorbia lactea Haw. Nombre común: "Lechosa africana". c. Caladium bicolor (Aiton) Vent. Nombre común: "Corazón de María". d. Scindapsus aureus Engler. Nombre común: "Teléfono". e. Xantasoma yucatanensis Englen. Nombre común: "Makal". 
JS Flores, GCO Canto-Aviles, AG Flores-Serrano.

pocas investigaciones referente a plantas tóxicas en el humano, y las reportadas y documentadas en hospitales y clínicas son escasas (1). La mayoría de la información recopilada se obtuvo de los curanderos tradicionales de las comunidades mayas, quienes conocen las plantas, sus usos y efectos en la salud y, en ocasiones, también conocen los antídotos que se pueden obtener de otras plantas $(7,8)$.

Por otra parte la cantidad de plantas tóxicas existentes en la Península, representa el $20 \%$ de las que se reportan para todo México (1), y este número es mucho menor que el encontrado en otros estados de la República (6). La revisión bibliográfica reveló que la toxicidad mayormente documentada es la que produce efectos en la piel por contacto con plantas urticantes.

Se observó que la mayoría de las plantas tóxicas encontradas pertenecen a 5 familias: Euphorbiaceae con 15 especies, Araceae con 9, Anacardiaceae con 4, Apocynaceae y Solanaceae con 3 especies cada una. Asimismo, se observó que el $50 \%$ de las especies tóxicas encontradas son plantas ornamentales. Otros tipos de vegetación imperantes fueron matorral de duna costera (2 especies), selva baja y mediana (12 especies), vegetación secundaria (15 especies), huerto familiar (6 especies) y cerca viva (7 especies).

Puesto que la mayor parte de las plantas tóxicas encontradas son ornamentales, es de suma importancia que la población conozca estas plantas, para que así puedan prevenir la intoxicación de niños, principalmente, quienes son los más propensos a llevárselas a la boca. En la figura 2 pueden observarse 4 ejemplares de la familia Araceae, que es una de las más empleadas como ornamento.

Las plantas de esta familia gustan de la sombra, por lo que suelen encontrarse en el interior de las casas y en jardines. La intoxicación por estas plantas ocurre generalmente por cortar hojas o tallos, y tocar después la piel, este contacto provoca comezón, excoriaciones e inflamación. Si la planta fuera masticada o introducida en la boca, puede inflamar las mucosas y producir asfixia. Un primer auxilio es lavarse con jabón, pero lo mejor es evitar cortarlas, para lo cual se requiere el saber reconocerlas.

Una familia con efectos muy parecidos a Araceas es la de las Commelinaceas, cuyas especies producen irritación y quemaduras, en piel y mucosas. Estas plantas también son ornamentales. Otras familias que producen quemaduras en la piel son: Anacardiaceae, Apocynaceae, Araceae y Asclepiadaceae.

Otras plantas con efecto tóxico a la piel, son las que tienen glándulas con pelos urticantes (espinas muy finas), los cuales producen sustancias que contienen oxalatos; esta sustancia es inyectada al organismo a través de los pelos urticantes, que actúan como agujas hipodérmicas que se clavan y se rompen, quedando insertadas en la piel; entre éstas se tienen especies de las familias: Urticaceae, Loasaceae y Euphorbiaceae.

La familia Anacardiaceae también tiene especies, cuya resina (látex) provoca quemaduras en la piel y mucosas, de esta planta, algunas de ellas pueden producir graves lesiones, tal es el caso de las provocadas por Che che'en (Metopium brownei) y Sak cheche'en (Rhus radicans); se ha documentado que las personas alérgicas pueden presentar quemaduras aún estando lejos de estos árboles. Puesto que son silvestres debe tenerse cuidado de no estar cerca su sombra cuando se visita el campo.

Cuando ha habido contacto con la resina del Che che'en, se recomienda preparan un baño con corteza y hojas del árbol llamado Chacah (Bursera simaruba), el cual hace el papel de antídoto, y evitando que aparezcan quemaduras. Otras familias que pueden afectar con su látex son: Asclepiadaceae, Euphorbiaceae y Papaveraceae; de éstas, las especies de la familia Euphorbiaceae son las que pueden causar daños más severos, por ejemplo: Euphorbia lutecens, E. tirucalli, además, estas especies pueden tener otros efectos en el organismo al ser ingeridas, tales como vómitos, trastornos estomacales, trastornos nerviosos,

\section{Revista Biomédica}




\section{Flora yucatanense tóxica.}

asfixia, coma y hasta la muerte.

Las familias Solanaceae y Papaveraceae también presentan especies que causan grandes trastornos nerviosos al ser ingeridas, como locura, y en casos extremos, puede producir la muerte; entre ellas se encuentran las especies Solanum mammosum, Hura polyandra y las especies del género Datura. Otra especie cuyo tubérculo muy tóxico es Zamia lodigesii, la cual puede causar la muerte al ser consumida.

En términos generales se encontró que, en la Península de Yucatán, la cantidad de especies tóxicas para el humano es mucho menor que el reportado para animales. Esto se debe a que los animales son menos selectivos que el humano. Los animales más susceptibles a ser intoxicados por especies nativas de la Península son los traídos por los europeos.

Cabe señalar que en el presente trabajo no se han considerado aquellas plantas que causan daño físico debido a sus espinas, como sucede con algunas Leguminosas y Cactaceas. Asimismo, es importante mencionar que tampoco se han tomado en cuenta aquellas plantas que en hospitales, clínicas y Cruz Roja del estado, han sido reportadas como causantes de asfixia por atragantamiento, especialmente con sus semillas.

\section{REFERENCIAS.}

1.- Aguilar-Castro A. Plantas tóxicas de México. México: Instituto Mexicano del Seguro Social; 1982.

2.- Sosa V, Flores JS, Gray R, Lira R, Ortiz J. Etnoflora Yucatanense. Lista florística y sinonimia maya. Fasc. No. 1. Xalapa: Instituto Nacional de Investigación sobre Recursos Bióticos; 1985.

3.- Canto-Avilés GCO. Plantas de la flora yucatanense reportadas con alguna toxicidad. Tesis de Licenciatura. Facultad de Química, Universidad Autónoma de Yucatán; 1990.

4.- Flores JS, Espejel I. Etnoflora Yucatanense. Tipos de Vegetación de la Península de Yucatán. Fasc. No. 4. Lic. en Biología. Facultad de Medicina Veterinaria y Zootecnia, Mérida: Universidad Autónoma de Yucatán; 1994.
5.- Flores JS, Narave H, Vovides AP. Etnoflora Yucatanense. Gymnosperma, Taxonomía y Etnobotánica. Fasc. No. 5. Lic. en Biología, Facultad de Medicina Veterinaria y Zootecnia. Mérida: Universidad Autónoma de Yucatán; 1994.

6.- Avendaño S. Plantas reportadas como tóxicas para el ganado en el estado de Veracruz. Tesis de Maestría, Facultad de Ciencias, UNAM; 1997.

7.- Avendaño S, Flores JS. Registro de plantas tóxicas para ganado en el estado de Veracruz, México. Vet Mex 1999; 30:79-94.

8.- Flores JS, Cantún-Balam M de J. Importance of plants in the cha'a chaak Maya ritual in the Peninsula of Yucatan. J Etnobiol 1997; 17: 97-108. 